Extra-academic transdisciplinarity and scientific pluralism : what might they learn from one another?

Koskinen, Aino Varpu Inkeri

2016

Koskinen , A V I \& Mäki , I U 2016 , ' Extra-academic transdisciplinarity and scientific pluralism : what might they learn from one another? ' , European Journal for Philosophy of pÿScience, vol. 6 , no. 3 , pp. 419444 . https://doi.org/10.1007/s13194-016-0141-5

http://hdl.handle.net/10138/172924

https://doi.org/10.1007/s13194-016-0141-5

Downloaded from Helda, University of Helsinki institutional repository.

This is an electronic reprint of the original article.

This reprint may differ from the original in pagination and typographic detail.

Please cite the original version. 
The final version of this article was published in the European Journal for Philosophy of Science, October 2016, Volume 6, Issue 3, pp 419-444.

\title{
Extra-Academic Transdisciplinarity and Scientific Pluralism: What might they learn from one another?
}

\author{
Inkeri Koskinen and Uskali Mäki
}

\begin{abstract}
The paper looks at challenges related to the ideas of integration and knowledge systems in extra-academic transdisciplinarity (TD). Philosophers of science are only starting paying attention to the increasingly common practice of introducing extra-academic perspectives or engaging extra-academic parties in academic knowledge production. So far the rather scant philosophical discussion on the subject has mainly concentrated on the question whether such engagement is beneficial in science or not. Meanwhile, there is quite a large and growing literature on extra-academic TD, mostly authored by non-philosophers, seeking to develop TD research practices. We examine this literature in the light of recent discussions in pluralist philosophies of science. Some philosophical pluralists see the increase of extra-academic collaboration and participation in science as a potentially positive development. However, certain views promoted in the non-philosophical literature on extra-academic TD appear problematic in the light of the pluralistic discussions. For instance, the literature on TD appears to be overly optimistic with regard to integration, and the notion of knowledge systems used in it is problematic. We believe it would be worthwhile for scientific pluralists sympathetic to the aims of TD to look more closely into the complex settings in which extra-academic collaboration and participation happens in actual TD projects, and to offer constructive criticisms, exploiting insights developed within pluralist philosophy of science.
\end{abstract}

Keywords. Extra-academic transdisciplinarity, scientific pluralism, participation, integration, knowledge system, power asymmetries

\section{Introduction}

This paper looks at two bodies of literature in relation to one another. Both discuss extra-academic participation in academic research, but thus far these literatures have proceeded independently within different disciplinary frameworks. One deals with extra-academic transdisciplinarity and is mostly authored by non-philosophers, while the other consists of work by some 
philosophers on scientific pluralism. We propose bringing the two bodies of literature in contact with one another.

Of the TD literature, we have chosen handbooks, programmatic articles, and empirical case studies, and identify two issues - the possibility of integration and the idea of knowledge systems - for more detailed analysis and elaboration. We critically consider this literature and these issues in the light of arguments developed in the pluralist literature, focusing on questions related to the epistemic assessment of TD projects. Of the pluralist literature, we concentrate on the work of two philosophers, Philip Kitcher and Alison Wylie, who have offered explicit accounts that touch on the role of extra-academic perspectives in science (we occasionally consulting others too, such as Helen Longino, Jeroen Van Bouwel, and Sandra Mitchell). We suggest that pluralist philosophies would benefit from paying more attention to the actual, evolving TD research practices. It would be worthwhile for philosophers of science to take notice of the diverse settings in which extra-academic participation happens in actual TD projects - of which empirical case studies of TD projects may be informative. It appears these literatures can learn from one another.

The idea of engaging extra-academic parties in academic knowledge production is part of the new rhetoric of relevance in research policy. It is no longer just an idea or mere rhetoric - it is becoming an important practice as extra-academic agents are being given various roles in shaping, producing and applying research. The perceptions of this trend vary from viewing it, at one extreme, as a panacea that will re-establish the societal relevance of science, to considering it, at the other extreme, a "tyranny of participation" (Cooke and Kothari 2001) that leads to unjust exercise of power, or threatens to corrode the traditional ideals of scientific rigour and objectivity (Boghossian 2006).

Extra-academic participation is especially well established in transdisciplinary research that attempts to tackle complex real-life problems by integrating inputs from many different sources. The incorporation of extraacademic values, interests, and knowledge in research is seen by many as a necessary step in the development of academic research if it is to be of help in meeting such multifaceted challenges as climate change and global poverty, innovation and competitiveness. There is now a strong normative urge to develop more practically relevant and socially inclusive research practices. Powerful agencies of research policy and research funding, both within and outside of universities, increasingly favour broadly collaborative and participatory practices that engage extra-academic parties such as businesses, local communities, NGOs and indigenous people.

There is a vast and rapidly growing literature on extra-academic transdisciplinarity (TD), mostly produced by non-philosophers. Some of this literature is self-reflective as the authors may themselves seek to conduct 
transdisciplinary research. ${ }^{1}$ These reflections often build on systems theory and a "Mode-2" concept of knowledge production, but also on other approaches such as the idea of "postcolonial" research (Nowotny, Scott \& Gibbons 2001, Hirsch Hadorn \& al. 2008, Pohl 2008, Zierhofer and Burger 2007). However, no generally accepted definition of extra-academic TD has been settled. Some of the basic notions used in the debates over these issues, such as integration and knowledge system, remain as yet equivocal. Most of the literature that seeks to address conceptual and normative issues related to transdisciplinarity is primarily programmatic, envisioning needs and outlining vague guidelines for this kind of research. On the other hand, there are many empirical case studies on transdisciplinary projects - often focusing on their difficulties and failures but these typically say little or nothing about the conceptual and normative issues. One would expect philosophical investigation to be helpful in filling in these gaps.

Turning then to the second body of literature, that in philosophy of science, we can first note that, for the most part, scientific pluralists concentrate on intraacademic issues. We hasten to add that some of their attention has also been attracted by issues of extra-academic collaboration and participation. Several pluralists hold rather favourable attitudes towards attempts to democratise scientific knowledge production by introducing collaborative and participatory approaches. We focus on two different paths through which pluralist arguments may lead to the defence of extra-academic agents influencing scientific knowledge production, or even taking part in it. One of them derives from Philip Kitcher's $(2001,2011)$ account of the role of science in a democratic society in which he endorses a view that can be interpreted as a defence of limited extraacademic participation in science. His arguments are related to a broader discussion about upgrading the possible contributions by lay people to research, suggesting that lay people may be stakeholders who should have their voice heard especially in policy-relevant research, or can be considered well-informed experts on issues that researchers wish to study (Van Bouwel 2009, Fehr and Plaisance 2010, Solomon 2009). Another related endorsement of extra-academic collaboration and participation stems from feminist philosophy of science and feminist social epistemology. Drawing on this source, Alison Wylie (2015) has recently offered a pluralist argument according to which extra-academic communities may be able to offer epistemically important criticism from their unique standpoint.

There is an obvious gap in the pluralist literature: in contrast to the nonphilosophical literature on extra-academic TD, scientific pluralists in philosophy have not yet paid much attention to actual TD practices. The arguments Kitcher

\footnotetext{
${ }^{1}$ Note that what we call 'extra-academic transdisciplinarity' is often called just 'transdisciplinarity' in this literature. Our choice manifests the idea that there are interesting versions of intra-academic transdisciplinarity, too.
} 
and Wylie offer are not aimed at tackling problems that arise when scientists work together with extra-academic agents. They also proceed from a relatively limited idea of the setting in which such collaboration or participation occurs. All this results in a rather narrowly focused examination of extra-academic participation, leaving many hot issues in the shadows. It will be useful to consult the non-philosophical literature in bringing those issues under the spotlight. On the other hand, there are other ongoing discussions on pluralism that - even though not directly addressing TD issues - could be relevant for the scrutiny of extra-academic TD. We will examine the recent debates on the possibility of integration, and the ongoing discussion on what we call the pluralistic version of the demarcation problem. We argue that arguments presented in these discussions can be applied to issues that are central in the TD literature: the ideas of integration and knowledge systems. We also note that by paying more attention to actual TD research scientific pluralists could positively contribute to the development of the evolving research practices.

We start with a sketchy portrayal of extra-academic transdisciplinarity in comparison to the two pluralist views on extra-academic participation we selected for consideration. Then we focus on two sets of issues about integration: one is about the integration of social values with scientific values; the other is about the integration of diverse scientific approaches. In TD projects these two are seen as inseparable parts of one and the same process, whereas in pluralist accounts they are generally treated separately. Then we add extra-academic knowledge to the picture, and analyse specific ways in which the integration of academic knowledge and extra-academic knowledge may fail because of unresolvable epistemic conflicts. Here we introduce the problematic notion of knowledge systems used in the TD literature, and suggest how some ideas developed in pluralist philosophies of science can be fruitfully used to analyse situations of epistemic conflict in extra-academic TD.

\section{Transdisciplinary and pluralist views on extra-academic participation}

The growing demand for extra-academic transdisciplinarity is part of the ongoing process of intensifying science-society relations whereby science is expected to be of more direct and swift relevance to the rest of society. The key idea is jointly manifested by the two components of the label 'transdisciplinarity' and 'extra-academic'. No single discipline alone is able to meet the expectations of practical relevance, nor are academic disciplines by themselves, whatever their mutual configurations. Several academic disciplines together with extra-academic contributors are required.

Extra-academic transdisciplinarity is called to solve problems and to meet challenges that are too complex for any one academic discipline to tackle and that are not defined within any monodisciplinary frames. The problems and 
challenges are typically not identified in disciplinary terms by disciplinary communities - they may not be recognized as urgent research problems within the prevailing frameworks of disciplinary research. The problems and challenges are rather identified as such -- as problems and challenges -- worth attention and solution, in non-disciplinary terms, and this happens in large part by extraacademic agents such as political and administrative authorities, businesses, NGOs, and local communities. These are also among the extra-academic agents that are supposed to contribute to the solutions of the problems. Some of the challenges are global, such as biodiversity loss, climate change and global poverty, while others are more local or regional, such as urban and landscape design, improvement of health care and sustainable development of tourism (Brown \& al. 2010, Hirsch Hadorn \& al 2008, Hirsch Hadorn, Pohl and Bammer 2010, Leavy 2011, Russell, Wickson and Carey 2008, Zierhofer and Burger 2007, Mobjörk 2010).

Different interests and values that are at stake in a TD project are often accompanied by different viewpoints, conceptualizations, explanations and representations. This is so especially in the case of so called "wicked problems", that is, problems that are very complex and difficult, and perceived very differently by the various groups they touch. Different disciplines interpret the problem in their own ways, and including the extra-academic communities to whom it is a problem only widens the array of potentially conflicting interpretations. Transdisciplinary research is seen as a way to create a shared, multifaceted understanding of the wicked problem, and thus to be likely to arrive at the best available solution (Brown et al. 2010).

The idea of integrating knowledge from different sources in order to offer solutions to pressing societal or environmental problems has been articulated in terms of systems theory and the "Mode-2" concept of knowledge production (Hirsch Hadorn et al. 2008, Gibbons et al. 1994, Nowotny, Scott \& Gibbons 2001). The problem fields are seen as complex systems, parts of which are studied by academic disciplines and approaches. An adequate understanding of a particular problem at hand, and the development of a solution, require the collaboration of researchers representing different theories and approaches in a solutionoriented research project. TD has been strongly influenced also by contemporary ideas about the proper relationship between academic researchers and the public, suggesting a normative urge to develop more socially inclusive research practices. Not only academic researchers, but also extra-academic agents may have valuable perspectives and knowledge related to the problem at hand, or they may be in a position to highlight some important aspects of it. When a research project aims at producing policy-relevant knowledge and offering solutions to pressing real-life problems, it is now often considered that the people or interest groups whose lives the problem touches should take actively 
part in the whole research process to ensure that their viewpoints and interests are taken into account.

The available definitions of transdisciplinarity are not uniform (see e.g. Carew and Wickson 2010, Pohl 2011, 619-620). They cite multiple attributes, but rely on different subsets of these. The definitions can be organized as a series with an expanding set of attributes cited, and a shrinking scope implied, so that the more numerous the attributes cited in a definition, the fewer instances there are that satisfy the definition. Splitting a little further than is usual in the literature gives us the following list of attributes:

1. Transcending scientific disciplines and/or approaches within academia

2. Integrating academic disciplines and/or approaches with one another

3. Addressing and attempting to solve socially and practically relevant issues

4. Involvement of extra-academic agents in various roles

5. Involvement of extra-academic knowledges

6. Involvement of extra-academic values and interests

7. Integrating academic and extra-academic knowledges and values

8. Serving the common good (or some such idea of a normative goal)

We will consider these attributes in relation to the arguments regarding extraacademic collaboration or participation in science presented by Kitcher and Wylie. First a few words about scientific pluralism in general.

Scientific pluralism is a normative principle or statement about plurality in science. Pluralism either justifies the actually obtaining (kind and degree of) plurality or recommends that there be (higher-than-actual degrees or otherthan-actual kinds of) plurality in science (Mäki 1997). Pluralism is always pluralism about some item $X$, and the value of $X$ can range widely, from reality and truth to belief and knowledge, from theories and models to methods and methodological principles, from explanations and sources of data to research styles and strategies, from questions and interests to goals and values, from institutions and organisations to agents and informants of inquiry, and so on. This range of items gives rise to a variety of types of pluralism. Further sub-types are based on the sorts of reason one cites in support of pluralism about some item - such as the importance of pursuing a comprehensive account of a complex phenomenon by combining a multiplicity of models; and the usefulness of employing multiple perspectives in error elimination (ibid.). Other dimensions include ideas about how such multiple items are related to one another. Among these, of relevance here are insulation: the items exist in separation from each other, they co-exist without consequential contact; interaction: the items interact, perhaps cross-fertilize or cross-check one another; and integration: the items are 
being integrated into relatively coherent systems (cf. Chang 2012:269, Van Bouwel 2015, Wylie 2015). And finally, another relevant dimension ranges from intra-academic (including intradisciplinary and interdisciplinary items) to extraacademic (encompassing a diverse variety of items, from business interests to indigenous knowledge systems, and so on).

We can now pick out and list those ideas that are relevant for our purposes. Pluralist philosophies of science can then be seen as endorsing permutations of such elements.

a. Plurality of epistemic items (theories, explanations, data etc)

b. Plurality of pragmatic items directing research (questions, problems, goals, values, interests, etc)

c. Plurality of methodological items (methods, styles of inquiry, standards of quality, etc)

d. Plurality of agents of inquiry

e. Plurality of intra-academic items a-d

f. Plurality of extra-academic items a-d

g. Plurality of items in mutually tolerant insulation

h. Plurality of items in mutual interaction

i. Plurality of items integrated with one another

Pluralist philosophers of science mostly concentrate on a, b, c, and/or d of the intra-academic kind (e). Our focus here however is on two versions of scientific pluralism that defend the incorporation of extra-academic items ( $f$ ) into academic research. There are, as noted, at least two paths through which a pluralist stance may lead to the argument that extra-academic participation, or the integration of extra-academic viewpoints, is a good thing in science, a recommendable line in organising research. Along the first path, extra-academic parties serve as stakeholders who bring in goals and values and interests that guide problem-setting, subsequent research, and the use of its results. In other words, they serve to fix the pragmatic context of any particular piece of inquiry; and there is a plurality of such contexts. This connects with pluralism in an obvious manner. Any piece of knowledge is pragmatically constrained in that it serves one set of purposes rather than some other set. The epistemic goods produced by different scientific approaches may be well suited for different purposes (see Longino 2013; Kellert, Longino and Waters 2006). Thus differences between diverse approaches can be based on differences in their (typically implicit) values regarding desirable tasks and goals: each emphasises the importance of the particular purposes for which it is best suited, so plurality is justified (Kitcher 2011, 36). 
Insofar as academic research is taken to have the responsibility for producing knowledge for the use of the rest of society, researchers should not, just by themselves, decide which approaches should be funded and advanced, and when, and which purposes thus served. Philip Kitcher has defended the view (combining b, e, f and i) that scientific values should be integrated with social values in a process where it is decided case-by-case which pragmatic purposes research should serve (Kitcher 2001, 2011, see also Van Bouwel 2009, Cartieri and Potochnik 2014, Douglas 2007). Kitcher's rather weak pluralism stresses the importance of taking heed of extra-academic interests and perspectives in giving direction to research, thereby endorsing more broadly democratic ways of setting the agenda of knowledge production within academia (without however subjecting intra-academic epistemic and methodological items to democratic determination). As Mark Brown $(2004,2013)$ has noted, it is somewhat ambiguous whether Kitcher actually suggests the involvement of extra-academic agents (d) in scientific knowledge production or not. Kitcher (2011) himself describes his account as an attempt to chart ways in which scientific expertise can be integrated with democratic values (i). This path is in accordance with attributes 3, 6 and 8 (and maybe 4) concerning TD that we listed above.

The second path from pluralism to extra-academic participation suggests engaging extra-academic partners as knowledgeable experts or epistemically useful critics, not just holders of values and interests. As Stephanie Solomon (2009) stresses, the role of extra-academic agents as stakeholders is very different from that of experts. Lay people can be well informed experts on an issue that researchers wish to study. Moreover, they might be able to offer epistemically important criticism from their unique standpoint. Alison Wylie's (2015) recent analysis of the potential epistemic advantages of collaborative practices and the use of indigenous knowledge in archaeology, combines these two ideas. The latter idea is implied by the view that several pluralists hold, namely that allowing for a variety of critical viewpoints and approaches is beneficial in science (e.g. Longino 1990, 2002a, Kitcher 1993, Wylie 2015). Among them, Wylie has explicitly extended this beyond intra-academic positions, arguing that extra-academic approaches to a given issue may also be epistemically useful. Compared to Kitcher's view, Wylie's is more inclusive, as she welcomes not only interests and values (b), but also epistemic (a) and methodological (c) contributions from extra-academic agents (d). However, unlike Kitcher, she is content with interaction (h), so does not entertain the greater ambitions of integration (i). This second path is in accordance with attributes 4 and 5 in the TD list.

So at least some philosophical advocates of scientific pluralism explicitly favour some idea of extra-academic participation in academic research. The main questions in the philosophers' discussion deal with the reasons why, and the ways in which, the extra-academic agents could and should take part in academic 
knowledge production. Here we want to raise another set of questions and draw attention to the setting in which this participation is typically thought to occur. This indeed needs the attention since the assumed setting tends to be quite simplified and idealized, as we will see when comparing it to what is ordinarily the case in actual extra-academic TD. We will provide the comparison in terms of two tables, but we first cite a few examples to give a flavour of the simplifications.

One common assumption is that when scientists collaborate with extra-academic agents, the most prominent social division is precisely that between these two communities, thereby suppressing or marginalizing divisions within them (see e.g. Kitcher 2001, 2011, Solomon 2009, King, Morgan-Olsen and Wong 2016, Wylie 2015). Another popular assumption, exemplified by the archaeological projects Wylie discusses, is that the extra-academic agents do not have socially established roles as producers of knowledge, and that they may represent socially marginal communities. Yet another assumption simplifies the setting by assuming that there are no epistemic conflicts between the academic and extraacademic communities. This may sound odd given that Kitcher (2001) and Longino (2013) among others observe that epistemic conflicts between these communities are perfectly possible. For instance, certain dominant research approaches in the study of human sexuality and aggression are not in line with the epistemic interests of some of the subjects being studied (Longino 2013). However, this general admission does not appear to apply throughout with equal weight: when explicitly commenting on extra-academic collaboration and participation, the pluralists we discuss here tend not to concentrate on such conflicts. Rather, they are set to defend the very idea of collaboration and participation against critics who worry about issues such as relativism (Wylie 2015). Sometimes this may be a result of the still lingering echoes of the "Science Wars"; indeed, Kitcher discusses them in his 2001 and 2011 books, thereby setting this as the motivating context for his pluralist argument.

Table 1 summarises the usual assumptions about the setting in the pluralist philosophers' discussion on extra-academic participation - call it pluralist philosophers' assumed setting.

\begin{tabular}{|l|l|}
\hline Participants & $\begin{array}{l}\text { There are two relevant groups: the researchers and the extra- } \\
\text { academic agents. }\end{array}$ \\
\hline $\begin{array}{l}\text { Status as } \\
\text { producers of } \\
\text { knowledge }\end{array}$ & $\begin{array}{l}\text { The researchers have a socially established role and a clear } \\
\text { institutional status as producers of knowledge, whereas the } \\
\text { extra-academic agents do not. }\end{array}$ \\
\hline $\begin{array}{l}\text { Power } \\
\text { asymmetries }\end{array}$ & $\begin{array}{l}\text { In case there is an acknowledged power asymmetry, the } \\
\text { researchers are in a (social, though not necessarily financial) } \\
\text { position of power in relation to the extra-academic agents. }\end{array}$ \\
\hline
\end{tabular}




\begin{tabular}{|l|l|}
\hline $\begin{array}{l}\text { Epistemic } \\
\text { conflict }\end{array}$ & $\begin{array}{l}\text { There may be unresolvable epistemic conflicts between the } \\
\text { different groups and subgroups, but such conflicts are not } \\
\text { central in the literature discussing extra-academic } \\
\text { collaboration and participation. }\end{array}$ \\
\hline Value conflict & $\begin{array}{l}\text { There may be unresolvable value conflicts between the } \\
\text { different groups and subgroups, but such conflicts are not } \\
\text { central in the literature discussing extra-academic } \\
\text { collaboration and participation. }\end{array}$ \\
\hline
\end{tabular}

Table 1 - Setting assumed in pluralist PoS when discussing extra-academic participation

Now let us consider actual extra-academic TD practices. The participants in a TD project may include several extra-academic agents and representatives of many scientific disciplines or academic approaches. In contrast to the pluralist philosophers' assumed setting, some of the extra-academic participants may be in positions of power in relation to the researchers and to other extra-academic agents. Indigenous and local communities may often be positioned differently from, say, big multinational companies or mighty political powers ${ }^{2}$.

It is also perfectly possible that some of the extra-academic agents have socially established roles and even institutional statuses as recognised producers of knowledge. For instance, companies developing medical technology (Rip 2008), or important NGOs such as Greenpeace (Held and Edenhofer 2008), are in such a position that their knowledge claims are often taken seriously in the surrounding society.

Many pluralist philosophers join other commentators in emphasising that smooth integration of academic disciplines is often too much to hope. Not all intra-academic epistemic conflicts are presently resolvable and some may never be resolvable (Longino 2013, Kellert, Longino and Waters 2006). However, when discussing extra-academic participation, pluralist philosophers typically do not concentrate on unresolvable or hard to solve epistemic conflicts between academic researchers and extra-academic agents. Such conflicts are nevertheless possible, and we will discuss the issue in more detail in section 4 . And as we shall

\footnotetext{
${ }^{2}$ Such asymmetries were probably involved in a project that built a framework that allowed biophysicists and the representatives of indigenous communities in Queensland, Australia, to create indicators needed for the protection and development of a cultural landscape (CullenUnsworth \& al. 2011). There were thirteen partners/stakeholders listed as participating in different ways in the project. They included two indigenous communities, several corporations, several official commitees (for instance the Australian representative from the UNESCO World Heritage Committee), the Commonwealth Scientific and Industrial Research Organisation CSIRO, and the Australian Institute of Aboriginal and Torres Strait Islander Studies (ibid., 5). It is unlikely that the powers possessed by these different partners was perfectly symmetrical, or negligibly asymmetrical - and it is clear that some of the extra-academic participants were in positions of power in relation to the researchers.
} 
see in section 3, academic researchers can often not avoid being influenced by, or taking part in, the diverse value conflicts that characterize TD projects.

Finally, the most significant dividing line in an extra-academic TD project is not always between the academic researchers and the extra-academic agents. In case there are several contributing groups, a variety of alternative divisions and alliances among them may be produced by existing power asymmetries, divergent roles as producers of knowledge, and diverse values and interests between the groups. A division more important than that between researchers and extra-academic agents might emerge, for instance, between the researchers and the authorities on one side, and a local community on the other; or between the researchers, NGOs and local communities on one side, and local industries and some political or administrative authorities on the other. It is also possible that academic researchers are divided into two or more disagreeing groups in a TD project, allying with different extra-academic agents, in which case the value conflict may be closely linked to an epistemic conflict between the rival groups of academic researchers.

In short, to use the same parameters as in Table 1, the setting in actual extra-academic TD projects can be described in the manner of Table 2.

\begin{tabular}{|l|l|}
\hline Participants & $\begin{array}{l}\text { There are several relevant groups: researchers from different } \\
\text { disciplines or fields or schools, and diverse groups of extra- } \\
\text { academic agents. The division between academic researchers } \\
\text { and extra-academic agents may be less prominent than some } \\
\text { other division between the participants. }\end{array}$ \\
\hline $\begin{array}{l}\text { Status as } \\
\text { producers of } \\
\text { knowledge }\end{array}$ & $\begin{array}{l}\text { Typically only some of the relevant groups have socially } \\
\text { established (but diverse) roles and institutional statuses as } \\
\text { producers of knowledge. }\end{array}$ \\
\hline $\begin{array}{l}\text { Power } \\
\text { asymmetries }\end{array}$ & $\begin{array}{l}\text { There may be complex power asymmetries between the } \\
\text { different groups; e.g. some of the extra-academic agents may } \\
\text { be in social and/or financial positions of power in relation to } \\
\text { the researchers and/or to other extra-academic agents. }\end{array}$ \\
\hline $\begin{array}{l}\text { Epistemic } \\
\text { conflict }\end{array}$ & $\begin{array}{l}\text { There may be unresolvable or hard to resolve epistemic } \\
\text { conflicts between the groups. }\end{array}$ \\
\hline Value conflict & $\begin{array}{l}\text { There may be unresolvable or hard to resolve value conflicts } \\
\text { between the groups. }\end{array}$ \\
\hline
\end{tabular}

Table 2 - Setting in actual extra-academic TD projects

There are thus some noticeable differences between the pluralist philosophers' assumed setting, and the settings in actual extra-academic TD projects. The setting assumed by these philosophers is just one amongst many possible ones, 
and probably not at all a typical one. This matters, as there are serious issues worth philosophical attention that arise in other kinds of settings. Considering the performance of pluralist philosophies of science, this may sound like a defeat, but we will be delighted to explain how this can be turned into a victory. In the next two sections we show how some ideas and arguments presented in pluralist discussions on intra-academic issues can be adapted for fruitfully addressing issues related to extra-academic participation that arise in the TD literature.

We will start by discussing the issues of integrating scientific and social values on one hand, and those in the integration of different academic representations, explanations and theories on the other. In pluralist philosophy of science these forms of integration are often discussed separately, whereas in the non-philosophical TD literature they are seen as indivisible parts of one and the same process. After this we turn to the idea of extra-academic agents as holders of valuable knowledge, and the associated equivocal notion of extraacademic knowledge systems.

\section{Integration in policy-relevant TD research}

In comparing and contrasting the two literatures it is useful to pay attention to the idea of integration. The notion of integration used in the TD literature tends to be quite comprehensive and ambitious, as it suggests merging axiological items with epistemic items: the axiological integration of social values with scientific values, and the epistemic integration of theories, explanations, representations, conceptualizations etc. deriving from different sources are considered inseparable, parts of one process. Both of these species of integration are discussed also in pluralist philosophies of science, but they are typically addressed separately, and the epistemic variant is considered mainly in intraacademic contexts.

The integration of social values with scientific ones is an important issue in ongoing philosophical discussions on the role of science in a democratic society, and on the role stakeholders should have in research. These discussions are largely based on the observation that value-judgements pervade scientific practice (Douglas 2007, Kitcher 2011), and that "commitments to factual claims and to value-judgements coevolve" (Kitcher 2011,36) in science. However, the integration of theories, explanations, or representations is usually not a central topic in these discussions. Instead, as we shall see, it is taken up in debates about unification and incommensurability.

In practice it might be difficult or impossible to separate the two species of integration. This is reflected in the TD literature that typically does not make an analytical distinction between them. In actual TD research they easily belong to the same, continuous process - as happens in some intra-academic scientific debates. However, in contrast to purely intra-academic contexts, extra-academic 
TD has certain prominent characteristics that make a difference. One needs to consider the consequences of characteristics such as these: non-epistemic values and interests are often openly in the forefront; there is a strong and urgent pressure to succeed in integration within a limited time span; and there are no established principles for quality assessment and no peer community to apply them. As we will see, these characteristics create potential difficulties in the assessment of TD research and may sometimes jeopardise the reliability of the produced knowledge. In order to analyse these difficulties it is important to distinguish between different types of integration. Thus we suggest using distinctions that can be found in the pluralist philosophical literature to identify and analyse problems in the TD literature. At the same time we suggest building stronger links between the two pluralist discussions where one or another of the two types of integration is an important topic.

Integration is often cited as an indispensable and integral part of transdisciplinary research, belonging to its "core methodology" (Pohl et al. 2008, 421). In order to create a functional solution to a complex problem, the problem has to be understood comprehensively, and its attempted solutions should reflect the interests of all relevant stakeholders and employ all the available knowledge from different sources. Three characteristics of integration envisaged in this literature are worth noting. First, rather ambitiously, integration is usually supposed to be realised through the building of a shared framework, to emerge gradually in the course of the research process. The framework is typically expected to include at least shared ideas of the aims of the project and a shared set of concepts, and it might involve for instance integrated methods and indicators and other conventions that guide inquiry. Second, the resulting framework belongs to a particular problem-oriented TD project - rather than being more broadly applicable. Hence any particular achievement in transdisciplinary integration is thought to be contingent and contextual, and therefore not generalizable or transportable as such to other cases. Third, the integrated framework does not belong to any of the contributing disciplines nor to any of the extra-academic agents (Leavy 2011, 28; Pohl et al. 2008, 416). This is indeed what 'transdisciplinarity' is generally intended to signify: the new framework transcends or transgresses those of the contributing parties.

The rather "integrated" notion of integration used in the TD literature differs from the ones used by pluralist philosophers of science. Two prominent defenders of two distinct pluralist views, Philip Kitcher and Helen Longino, may agree on the main argument related to the integration of social values with scientific values, but they disagree regarding the integration among scientific theories, representations and explanations - that is, scientific knowledge systems (Kitcher 2002, Longino 2002b; see also Kellert Longino and Waters 2006, Van Bouwel 2015). The notion of knowledge systems is indeed used in pluralist philosophies of science. For example, Jeroen Van Bouwel (2015: 151) 
defines scientific pluralism as "a normative endorsement of the multiplicity of knowledge systems" in different areas of science. Knowledge systems here are taken to be theories, models, research approaches, and the like (Van Bouwel 2015, Kellert, Longino and Waters 2006: xi, Mäki 1997), developed within academia. As we shall see in section 4 , this notion differs from the one used in the TD literature.

Both Longino and Kitcher hold that there may be reasonable but incompatible and rival scientific representations of presumably the same subject. Having reviewed scientific approaches to aggressive and sexual behaviour, Longino concludes that the different approaches produce portions of knowledge that are suited for different purposes. No approach can offer a more comprehensive picture than the others, so the choice of approach depends on "what one wants to do with the knowledge" (Longino 2013, 205, see also Kellert Longino and Waters 2006). In other words, the choice of approach depends on values. Kitcher argues that these kinds of reasonable value judgement pervade all levels of scientific practice. At all stages of the research process, researchers need to decide whether the probability for something is high enough to warrant a decision, whether something has been established well enough to go on, or whether the original goals of a project have to be altered due to some new observations (Kitcher 2011, 34-36; Douglas 2007). All such decisions are context dependent and include value judgements. Currently nearly none of these value judgements are made democratically. Supposing, as he does, that academic research should serve the society, Kitcher calls for more democratic decision making in science, and outlines what he calls "well-ordered science" (Kitcher 2001, 2011). Well-ordered science is his version of allowing for beneficial incorporation of extra-academic interests and values in academic research. It is supposed to ensure that social values influence research in a democratic manner. His account, as noted, is somewhat ambiguous, as it is not clear whether he calls for the participation of actual (though well tutored) extra-academic agents in public deliberations on the goals of science - or whether his account should be read as an description of ideal decision-making which should not be understood as a goal to be emulated (Brown 2004, 2013). Either way, when describing the role of extra-academic agents in well-ordered science, Kitcher assumes, by and large, the setting outlined in Table 1.

The possibility of integration of intra-academic knowledge systems is debated within the circles that promote pluralist philosophy of science. Integration is contrasted to unification, and it is often seen as an alternative to theory reduction (e.g. Mitchell 2004). Some, such as Kitcher (2002) and Sandra Mitchell (2004), would allow the possibility of integrating different scientific theories and explanations. Kitcher holds that even though "there is no coherent ideal of a complete account of nature", and "at any stage in the history of the sciences, it's likely that the representations accepted are not all consistent" 
(Kitcher 2002, 570-5711), integration is still in principle possible. Mitchell's (2004) focus is on the possibility of integrating findings related to a single phenomenon, and she takes local integration to be both possible and necessary. Others - Longino amongst them - however are more cautious about the possibility of integration. They consider it an open and empirical question whether our epistemic capabilities will ever allow us to integrate diverse representations of every phenomenon, as our ability to measure the interactions of diverse mechanisms and processes in complex systems is limited. Some phenomena might be so nebulous or complicated that a single, integrated representation is not in our reach. If so, the existence of many diverse and possibly incommensurable representations of the same phenomenon should not be seen as a failure. (Kellert Longino and Waters 2006, Longino 2002b, Longino 2013.)

In the pluralist accounts related to the integration of scientific knowledge systems it is typically assumed that the setting is of the following kind (Table 3).

\begin{tabular}{|l|l|}
\hline Participants & $\begin{array}{l}\text { There are several relevant groups (representing different } \\
\text { approaches, representations, models, theories, or the like), all } \\
\text { of which are academic. }\end{array}$ \\
\hline $\begin{array}{l}\text { Status as } \\
\text { producers of } \\
\text { knowledge }\end{array}$ & $\begin{array}{l}\text { All of the relevant groups have socially established roles and a } \\
\text { clear institutional status as producers of knowledge. }\end{array}$ \\
\hline $\begin{array}{l}\text { Power } \\
\text { asymmetries }\end{array}$ & $\begin{array}{l}\text { There may be some power asymmetries between the } \\
\text { different groups. }\end{array}$ \\
\hline $\begin{array}{l}\text { Epistemic } \\
\text { conflict }\end{array}$ & $\begin{array}{l}\text { It is debatable whether the different approaches, } \\
\text { representations, models, or theories can be reconciled } \\
\text { (presently or ever). }\end{array}$ \\
\hline Value conflict & $\begin{array}{l}\text { Different, incompatible or incommensurable approaches, } \\
\text { representations, models, or theories may reflect rival } \\
\text { schemes of values. }\end{array}$ \\
\hline
\end{tabular}

Table 3 - Setting assumed in pluralist PoS when discussing intra-academic integration of scientific knowledge systems

In this assumed setting, intra-academic power asymmetries may obtain. Some approaches are funded more generously than others and receive more public attention, and this may be so for dubious reasons (see e.g. Longino 2013). Sometimes the power asymmetries can lead to epistemically problematic situations of scientific dominance or imperialism (see Clarke and Walsh 2009, Mäki 2013). However, academic disciplines and research fields are institutionally recognized as having the undisputed status as knowledge 
producers even if intra-academic integration were to be unfeasible. In extraacademic TD the situation is more complex.

Due to stark power asymmetries and differences in the participants' statuses as producers of knowledge, the pressure to succeed in integration may be much stronger in extra-academic TD than in an intra-academic setting. This does not yet guarantee a high likelihood of success. While the declared ideal in TD projects is to reach a solution to the perceived problem such that both the values of all the participants and all relevant knowledge are taken into account, it may prove impossible to integrate them. A value conflict or an epistemic conflict (or a combination of the two) may prove to be insurmountable. In such cases the project either fails to reach a solution at all, or fails to settle on a consensus solution: one or more participants may leave the project (or, in practice, might never even join it), and a solution is reached without their contribution; or some participants' views may be suppressed or marginalized within the project, while others dominate or overrule. Such failures go against the inclusive and democratic ideals stressed in the TD literature (even though it may in reality end up happening under the mask of rhetorically manipulated quasi-integration). But also the other options are problematic.

An agent who retreats from the project may have a socially established status as a recognized producer or holder of knowledge. As shown in Table 2, this can be the case even if the agent is extra-academic. If so, its viewpoint can be taken into account in subsequent decision making even if it proves to be unfeasible to integrate its values and/or knowledge with the values and/or knowledge of the participants of the project. A situation like this could lead to two (or more) competing proposed solutions to the problem at hand. The values and knowledge of all the groups for whom the solution is of relevance are not represented in any of the proposed solutions, and so there is likely to be a conflict at the stage of policy decision making. This runs counter to the dominant doctrine of extra-academic TD that includes a preference for solutions that all such groups could accept, so anything less than this would be suboptimal.

If instead the agent not taking part in the project does not have a socially established status as a producer or holder of knowledge, it is likely that its values and knowledge are not well represented in the problem solution the project arrives at. On top of this intra-project weakness, the agent is likely to have slim chances of influencing those decisions also outside the project. This too goes against the inclusive and democratic ideals stressed in the TD literature.

These are however not the only reasons why integration is stressed in extra-academic TD. Some of the extra-academic agents might be in a position of power in relation to the researchers (in contrast to the pluralist philosophers' assumed setting). In some of the TD projects mentioned above it might be politically unthinkable for the researchers to give up on the attempt to integrate their own interests and approaches with those of the particularly powerful 
agents. If the researchers were to produce the needed, allegedly policy-relevant knowledge, but some such sufficiently powerful extra-academic agents would not accept their results, the offered solution would be less likely to be implemented. A result of a TD project that is a problem solution that has no chances of being implemented is a bad result, and the project is a failure. This fortifies the importance of integration.

As we can see, there are strong pressures in TD projects to succeed in integration. Failure to integrate may lead to the failure of the whole project: it may fail to reach a solution, or fail to adhere to its democratic ideals, or fail to influence policy. Furthermore, inspired by systems theory, the literature on TD is generally quite optimistic regarding the prospects of integration. Hence it is not surprising that the literature is full of confident statements about integration.

From a pluralist point of view this optimism seems excessive. Even modest forms of scientific pluralism would adhere to the view that existing scientific knowledge systems may not be integratable. When examining systems theory approaches in the study of behaviour, Longino (2013) notes the problem: the view that all factors in a complex system interact with each other is most likely correct in a metaphysical sense, but no integrated research approach manages to study more than a very small part of these interactions. Moreover, even if possible, in practice the integration of just a limited range of scientific approaches takes time and effort. An ideal (and non-existent) extra-academic TD project would manage to build a rich, detailed and fully shared framework that consists of a shared understanding of the relevant problem, shared values, shared concepts, shared ways of argumentation, shared ways of producing knowledge, and shared standards according to which knowledge claims are justified and results evaluated. As Henrik Thorén and Line Breian (2015) point out, the building of such a framework for the use of just one project is an unrealistic demand. Interdisciplinary integration is difficult enough even in permanent settings, and hasty attempts easily lead to pseudo-integration (see Van Der Steen 1993).

The integration of values may also be difficult. As Aant Elzinga (2008) points out, especially in cases where there are political tensions and conflicts of interest between the different extra-academic groups, a more attainable objective is the creation of a limited number of boundary objects or boundary concepts that can be used as means of communication between the groups. Such boundary objects do not need to be understood in exactly the same way by all groups involved in the project. They are both plastic and robust as they "have different meanings in different social worlds but their structure is common enough to more than one world to make them recognizable, a means of translation" (Star and Giresemer 1989, 393). Thanks to this duality of plasticity and robustness, they enable communication across intersecting social worlds. However, as the ambitions of a desirable TD project suggest seeking to combine 
the integration of values with the integration of scientific knowledge systems, this will not always be sufficient for a satisfactory solution.

Consider the idea of "wicked problems" in the light of the idea that different, incommensurable approaches, representions, models, explanations or the like may reflect rival schemes of values. A wicked problem is perceived differently by the different groups it touches, and the different approaches may involve different understandings of the problem. In such a setting it is very understandable that the two species of integration - the integration of values and the integration of knowledge systems - are seen as one and the same process. In practice it can be impossible to separate the processes that aim at integration of values and integration of knowledge. Yet the conflation of the axiological and the epistemic may result in problematic outcomes. If a working agreement on the values is reached by merely creating boundary objects, this may lead to forced and artificial attempts of integrating incommensurable academic approaches, and thereby to pseudo-integration.

In the TD literature integration is often considered according to a deliberative model of democracy (for critique and other models, see Van Bouwel $2009 \mathrm{~b}$ ): integration is to happen through mutual learning and deliberation. In the Handbook of Transdisciplinary Research Pohl et al (2008) distinguish three basic ways in which integration may happen: common group learning, deliberation by experts, and integration by a subgroup or an individual. The aim is to find an agreeable solution to a specific problem at hand, so it is crucial to find an understanding of the problem itself such that all participants can agree on its formulation. In contrast to many purely academic settings, the values are openly at the forefront. This has consequences for the way in which the notion of integration is understood, and for how it is thought to be realized. Given the strong pressure to succeed in integration in little time, there is a risk that common group learning and deliberation lead only to the creation of hollow boundary objects, and therefore to pseudo-integration of knowledge systems including academic ones. Moreover, as every TD project is supposed to create, as part of its integrated framework, its own criteria of assessment, it may be difficult to detect cases of such pseudo-integration even when they obtain.

The problem is especially acute if the integration is attempted just by a subgroup or an individual. Unfortunately, this cannot be easily alleviated as "there is not yet a well-established community of peers experienced in reviewing the quality of TD endeavours" and therefore "critically robust ways to discuss and evaluate the quality of TD research are underdeveloped and insufficient" (Wickson et al. 2006, 1055; see also Leavy 2011, 125ff). Given that TD research is broad and diffuse, evolving and context-specific (ibid.), it is not surprising that there are no agreed-upon ways available for reliably assessing the outcomes of TD projects. In other words, there might be no trans-project consensus attainable on how precisely to evaluate transdisciplinary research in general and 
individual projects in particular. Indeed, if each project is supposed to create its own framework, and then build on it, the establishing of a broadly operational peer community, distinct from particular transitory TD research teams, will prove difficult if not impossible. ${ }^{3}$

The tension between the philosophical pluralists discussed here and the extra-academic transdisciplinarians of the TD literature now emerges rather clearly. The pluralists stress the epistemic benefits of plurality, while the transdisciplinarians vehemently endorse comprehensive integration. The tension is particularly pronounced in the transdisciplinarians' stress on integration that has the consequence of marginalizing the benefits of plurality that is rather considered a nuisance to be suppressed. Philosophical pluralists recognize the difficulties of integration, but they are not blind to its desirability if conceived rather weakly and selectively. Sandra Mitchell (2003) endorses what she calls integrative pluralism - the integration of a plurality of partial models in addressing biological complexity, but this is an intra-academic and epistemic matter, devoid of the complications due to the involvement of extra-academic interests and contributions (see also Van Bouwel 2014). Kitcher has a broader view, suggesting that social values should be integrated with scientific values. Yet this is a rather weak idea of integration, as it does not go all the way to welcoming epistemic contributions from extra-academic agents. Wylie, in turn, welcomes epistemic contributions from extra-academic agents, but does not stress integration.

The transdisciplinarians keep reminding that practical or societal problems in need of solutions are often of the kind that no existing academic discipline or even several such disciplines can offer solutions that would satisfy all stakeholders. Integration with the relevant portions of extra-academic values and knowledge, reflecting the viewpoints and interests of those stakeholders, is therefore required. So there is often an urgent pressure towards comprehensive integration. Given the severe constraints - of time, competence, and contents of the items to be integrated - the outcome may fall far short of what should ideally transpire. Pseudo-integration may be an outcome of politically or commercially forced but uneasy and unstable compromise on values in combination with pretentious claims of having accommodated all relevant epistemic contributions in a balanced and coherent manner - while evaluative claims of this sort would be hard to justify in the absence of agreed-upon standards.

\footnotetext{
${ }^{3}$ Yet another potential risk is related to the deliberative way in which integration is supposed to happen, and to the lack of larger peer communities. As Miriam Solomon (2006) notes, consensusseeking deliberation may lead to so called "groupthink", in which dissenting individuals do not share their thoughts due to peer pressure and pressure from the authorities. Kristina Rolin (2011, 32) argues that even though this may happen in research teams, it is less likely to take place in larger, socially dispersed scientific communities. Thus the dissenting views will be expressed by members of the larger community. However, as in TD such communities do not exist, groupthink may go unnoticed.
} 
It could prove beneficial for the development of transdisciplinarity if pluralist philosophers of science sympathetic to at least some of the aims of extra-academic TD would pay more attention to questions related to the integration not only of scientific and social values, but of extra-academic epistemic contributions with scientific ones. This would likely require taking into account the complex settings of actual TD projects (e.g. those exhibited in Table 2). Here philosophers have a chance of learning from the empirical parts of the TD literature. On the other hand, philosophers are in a position to reciprocate. As we have shown, pluralist discussions of intra-academic integration can be fruitfully applied to the scrutiny of the integration of intra- and extra-academic perspectives and interests. We believe it would be welcome for philosophers of science sympathetic to the ideals of TD to focus on the potential epistemic pitfalls of actual TD endeavours. Normative philosophical work on these issues, highly relevant for extra-academic TD, is needed but presently missing, so there is demand for philosophers' services.

In the next section we will comment on a different problem. In the TD literature the actual process of integration is usually understood as resembling deliberative, democratic decision making. As noted, such an approach may not yield the desired outcomes when trying to integrate different scientific or academic inputs, as it ignores the possibility of irresolvable epistemic conflicts. Moreover, in an extra-academic setting there is another way in which mutual learning and deliberation can fail. It may be unfeasible to integrate academic knowledge with extra-academic knowledge. In collaborative and participatory research there may be specific kinds of epistemic conflict, ones that are less likely to occur in purely intra-academic settings.

\section{The idea of knowledge systems}

Many scientific pluralists hold that a variety of different approaches is epistemically beneficial in science, as it can help ensure that all research is under broad and intensive critical scrutiny (e.g. Longino 1990, 2002, Kitcher 1993). This idea can be extended to extra-academic contributions, too. The critical viewpoints of extra-academic agents may be epistemically beneficial. Drawing from social epistemology and feminist philosophy of science, Alison Wylie has recently analysed collaborative research practices in archaeology. She defends a form of "dynamic pluralism": encounters and interactions with indigenous people's knowledge systems can "destabilize entrenched epistemic and methodological norms" in academic archaeology (Wylie 2015, 204), and thus be potentially epistemically beneficial - provided those norms are in need of destabilization. Related ideas have been advanced in feminist philosophy of science when discussing forms of epistemic injustice, and the knowledge of socially marginalized people. Miranda Fricker (2007) distinguishes between 
testimonial and hermeneutical injustice: people belonging to socially marginal groups are not acknowledged as credible sources of knowledge; or the dominant majority lacks the conceptual resources needed for understanding their critical viewpoints (see also Fehr and Plaisance 2010, Wylie 2011, King, Morgan-Olsen and Wong 2016). Acknowledging such groups as potential sources of knowledge, and expanding conceptual frameworks so as to encompass their viewpoints, may prove not only ethically but also epistemically beneficial.

Recent decades have witnessed a growing interest in the knowledge held by people whose ideas used to be seen as perhaps interesting beliefs worth the attention of anthropologists as a target of study, but not as valuable knowledge akin to that produced by scientific inquiry. The situation has changed: 'knowledge' has become a flexible buzzword. It is popular today in many disciplines to be open to the idea of utilizing "different kinds of knowledge" in research, such as tacit knowledge, indigenous knowledge, artistic knowledge, the know-how of practitioners, and so on. At the same time postcolonialism has influenced many humanistic and social scientific disciplines and drawn attention to the knowledge systems of non-Western peoples.

As noted, the notion of knowledge systems - in plural - is used in pluralist philosophies of science. This notion is however restricted: knowledge systems are taken to be theories, models, research approaches, and the like developed within academia. In contrast, the notion of knowledge systems used when discussing extra-academic participation is broader. When it is combined with the stress on the very broadly conceived integration typical of the TD literature, and with the optimistic idea that integration is to happen through mutual learning and deliberation, it may lead to problematic outcomes. We believe that the possibility of academic and extra-academic knowledge systems not being amenable to integration requires more nuanced attention than it has yet received. As noted, such a possibility is discussed only in passing in the philosophical literature mentioned above (e.g. Kitcher 2001, Longino 2013). ${ }^{4}$ The question is, what to make of this possibility and how to examine it. We think interactive accounts of objectivity developed in pluralist philosophies of science and social epistemology are useful for elucidating our stance.

The use of extra-academic knowledge and the participation of extraacademic agents are among the core characteristics of extra-academic TD. In research seeking to be policy-relevant the role of academic researchers as the sole providers of valuable knowledge is seen as problematic. The perceived advantages of the involvement of extra-academic agents are both ethical and

\footnotetext{
${ }^{4}$ There are philosophers who criticise attempts to take extra-academic knowledge systems seriously (for instance Paul Boghossian, 2006), but they have not yet been active in offering ideas that could be of use in developing TD practices.
} 
epistemic: it is hoped to balance power asymmetries between academic researchers and the extra-academic agents; and to broaden the academic researchers' and the extra-academic agents' understanding of the issues at stake, by bringing in numerous perspectives and a rich array of detailed information needed for addressing the complex issues. It is not only their values that are to be taken into account in extra-academic TD, but their knowledge, too; and they are supposed to actively contribute to TD projects as partners.

Elsewhere there are important discussions on kinds of knowledge relevant here - such as tacit knowledge (Polanyi 1966, Collins 2010) and indigenous knowledge (e.g. Agrawal 1995, Harding 2011, Sillitoe \& Marzano 2009) - but these discussions are not strongly interconnected. Some ideas developed therein have been adopted to the literature on TD, but the differences in the ways in which kinds of knowledge can be understood and utilized, have not as yet gained much attention (see Raymond \& al. 2010). For a starter, we suggest a broad and very rough distinction between two ways in which extraacademic knowledge is approached in TD:

1) Bits and pieces. Extra-academic knowledge can be understood as bits and pieces that can in principle be incorporated into larger epistemic structures produced by academic research. They can originally belong to a community or to an individual. Once they are recognised and adequately interpreted, the hope is that they can be put into fruitful use in academic research. At least this is not prevented by them originally having been alien to academic aspirations. They can be a source of detailed information needed for specifying initial or boundary conditions of theoretical reasoning whose structure and foundations remain intact. Or they can play a role in critically challenging such structures by revealing inadequate assumptions on the side of the academic researchers, or in more constructively supplementing otherwise insufficient academic knowledge. Getting access to such useful bits and pieces may also require significant changes in research methods. Case studies of transdisciplinary projects often - implicitly or explicitly - refer to this way of understanding extra-academic knowledge.

2) Whole knowledge systems. At times extra-academic knowledge is understood more wholistically as distinct and complete knowledge systems that significantly differ from academic knowledge systems and therefore are not easily translatable or incorporatable into the latter. Theoretical contributions to the discussions about transdisciplinarity at times understand extra-academic knowledge in this way. It is far from clear what exactly 'knowledge system' is intended to mean, but the term is ubiquitous especially in the literature on indigenous knowledge. Expressions such as 'alternative epistemologies' and 'non-western paradigms' are also popular. We take it that in addition to a body of 
accepted beliefs, a knowledge system is characterised by some distinctive epistemic principles and values as well as associated standards for the justification of knowledge claims. As noted, individuals can have bits and pieces of knowledge, and they do not need to share them with other people. The idea of a knowledge system instead involves the idea of an epistemic community more or less in agreement on a system of beliefs and epistemic norms.

As can be seen, the notion of a knowledge system in the TD literature is broader and more vague than the one used in the pluralist philosophy of science. It often comes close to an anthropological notion of knowledge systems. They are taken to be organic cultural systems that need to be treated as wholes to be properly understood (Vayda, Walters and Setyawati, 2004). Detaching elements, for instance individual knowledge claims, from such a system for separate examination is considered misleading since they are bound to be misunderstood if taken out of their proper systemic context. Importantly, and in contrast to the respective notion in pluralist philosophies of science, the anthropological notion has not been developed for normative epistemic purposes. This is understandable given that the research questions in anthropology usually do not necessitate epistemic assessment of traditional knowledge systems (Koskinen 2014). Rather, the focus in anthropology is on understanding and translating, and a major goal is to avoid ethnocentrism (thus the use of the word "knowledge", not "belief"). These concerns are of course very relevant also in promoting and assessing extra-academic TD projects. Nevertheless, when extra-academic knowledge systems are to be integrated with academic ones, normative epistemic assessment becomes indispensable.

In some versions of extra-academic TD the notion of knowledge system is, however, loaded with another kind of normativity: "non-Western" knowledge, once marginalized, should be taken seriously, as it is at least as important as "Western" scientific knowledge - which, as Arun Agrawal (1995) notes, is often very problematically assumed to constitute a single coherent knowledge system. The view that there are "culturally specific ways of knowing" (Whitt 2009, xv) that have their own, distinctive epistemologies, is promoted in postcolonial literature, and it has been adopted also in some versions of extra-academic TD. The tone is sometimes sanguinely revolutionary: non-Western knowledge systems are supposed to liberate us from the limitations of ("Cartesian" and "dualistic") Western thought by opening up entirely new ways of thinking and knowing (e.g. Arabena 2010). The discussion is strongly linked to feminist and postcolonial philosophy, where non-Western knowledge systems are at times seen as "other cultures' sciences" (Harding 2011).

Then consider the notion of knowledge system in pluralist philosophy of science. Alison Wylie's pluralist account of the epistemically influential role that extra-academic knowledge systems could have in academic research is very 
moderate when compared to the revolutionaly visions of the TD literature. For instance, she does not speak for integration of knowledge systems, but rather more moderately for interaction and exchange between them. However, she does use a broader notion of knowledge systems than is typical in philosophy of science. According to her, indigenous communities can offer not only complementary expertise on certain issues, but also usefully critical viewpoints that are helpful in error elimination, in identifying and removing mistakes and imperfections in academic knowledge. Along these lines, Wylie proposes an extension to Longino's norm of "tempered equality of epistemic authority". The norm stresses the epistemic importance of listening to dissenting voices regardless of the speaker's social position in an epistemic community (Longino 2002 , 131). Longino however focuses mainly on academic communities. Wylie suggests that the norm should be explicitly extended beyond the boundaries of the academia:

In order to counteract the risks of insularity and the effects of dysfunctional group dynamics that can insulate foundational assumptions and norms of justification from critical scrutiny, well functioning epistemic communities should actively cultivate collaborations with external communities whose epistemic goals, practices, and beliefs differ from their own in ways that have the potential to mobilise transformative criticism. (Wylie 2015, 207).

Wylie talks about "alternative epistemic systems", "systems of knowledge" and "autonomous epistemic traditions", and she proposes extending the notion of knowledge systems so as to encompass systems that have earlier been of interest mainly to anthropologists. As her aim is to give an account of the potential epistemic advantages of broadly based interaction and collaboration, and given that she is not suggesting the integration of academic and extra-academic systems, it is understandable that she is not concerned about the possibility of serious conflicts between academic and extra-academic knowledge systems. Rather, she considers some worries about such conflicts to be exaggerated. Her account by and large assumes the setting described in Table 1.

Dominant versions of extra-academic TD do not merely aim at interaction and exchange between academic and extra-academic knowledge systems, but the more ambitious goal is their integration. In an ideal TD project the participant epistemic communities, academic and extra-academic alike, build a rich shared framework and work closely together at all stages of the research process: "problem identification, conceptualization and planning, data collection and interpretation, and the dissemination of the research results - including (co)authorship" (Leavy 2011, 88). In other words, the result is a merged epistemic community that has created an integrated knowledge system of its own. In our view, it is important to examine the potential epistemic pitfalls in research that aims at such integration. 
The possibility of irreconcilable epistemic conflicts between accepted scientific approaches and certain alternative stances, such as creationism, is the topic of yet another pluralist discussion: the one about the role and legitimacy of dissent and the limits related to uptake of criticism. This can also be seen as giving rise to what we identify as a pluralistic version of the demarcation problem. The question is whether there are criteria that would allow an advocate of a pluralist stance to rule out creationism and climate change denialism (and the like) as not being of the right kind of dissent that should be taken into account in objective scientific research. Many pluralists value dissent, as it may promote creativity and the detection of errors and may thereby lead to the improvement of scientific theories. However, some forms of dissent may be harmful, and even if scientists have an obligation to engage dissenting views, this obligation should not extend to just any dissent (Longino 1993, Longino 2002, Solomon 2008, Kitcher 2011, Melo-Martin and Intermann 2014, Biddle and Leuchner 2015). In this discussion the following setting is usually assumed (Table 4).

\begin{tabular}{|l|l|}
\hline Participants & $\begin{array}{l}\text { There are two relevant groups: the mainstream scientific } \\
\text { researchers and the dissenters. }\end{array}$ \\
\hline $\begin{array}{l}\text { Status as } \\
\text { producers of } \\
\text { knowledge }\end{array}$ & $\begin{array}{l}\text { The researchers as well as the dissenters have at least to } \\
\text { some degree socially established roles and an institutional } \\
\text { status as producers of knowledge. }\end{array}$ \\
\hline $\begin{array}{l}\text { Power } \\
\text { asymmetries }\end{array}$ & $\begin{array}{l}\text { There is no consistent power asymmetry across situations; } \\
\text { the dissenters may in some cases be in social or financial } \\
\text { positions of power in relation to the mainstream researchers, } \\
\text { while in some other cases the situation may be the opposite. }\end{array}$ \\
\hline $\begin{array}{l}\text { Epistemic } \\
\text { conflict }\end{array}$ & $\begin{array}{l}\text { There is a serious, perhaps irreconcilable epistemic conflict } \\
\text { between the two groups. }\end{array}$ \\
\hline Value conflict & $\begin{array}{l}\text { The epistemic conflict typically reflects an important conflict } \\
\text { of values. }\end{array}$ \\
\hline
\end{tabular}

Table 4 - Setting assumed in pluralist PoS when discussing problematic dissent

One response to the pluralistic demarcation problem is to refer to interactive accounts of objectivity that stress the qualities of epistemic communities (see Douglas 2007). For instance, Longino $(1990,2002)$ has formulated norms or criteria according to which the objectivity of research communities can be evaluated, and she uses them to delimit scientists' obligations towards dissenters such as creationists. The criteria include (1) the existence of venues for effective criticism, such as journals and conferences; (2) uptake of criticism: "beliefs and theories must change over time in response to the critical discourse taking place" (Longino 2002, 129); (3) publicly recognized standards of 
evaluation of observations and theories; and the already mentioned (4) tempered equality of epistemic authority: "the social position or economic power of an individual or group in a community ought not to determine who or what perspectives are taken seriously in that community" (ibid., 131). If the dissenters themselves do not strive to meet these criteria - if they for example do not take outside criticism into account - researchers are not obliged to use their time for what appear to be clearly fruitless debates with them.

Let us now consider an example: a conference organised by the Southern Interior Forest Extension and Research Partnership and En'owkin Centre (taking place in Quaaout Lodge on the Little Shuswap Reserve, near Chase, British Columbia, in March 2001), devoted to examining the possibilities of linking indigenous knowledge with scientific knowledge in natural resource management (Michel \& Gayton 2002). The aim of the conference was to recognize indigenous knowledge "as a knowledge system of equal importance to western science", and to incorporate it into ecosystem-based natural resource management (Michel 2002, 4). The participants included "indigenous knowledge keepers, scientists, resource managers, elders and academics" (Michel \& Gayton 2002, iv).

The conference proceedings make it clear that there were strong tensions between the participant groups. Not all believed the integrative goals to be achievable, mainly because of differences between scientific and indigenous knowledge systems, and because of power imbalances between scientists, academics and the resource managers on one side, and the indigenous knowledge keepers and elders on the other. Several indigenous participants feared it would lead to all too familiar epistemic injustices. A participant expressed the worry appositely: "If there is a gap, and the two systems are fundamentally different, then you can't link them. Or if you did, it would be onesided, with Western science calling the shots" (Michel \& Gayton 2002, 54). However, the organisers were keen on achieving their goals. This led to potentially problematic outcomes. The president of the conference describes the practices developed when planning the conference in the following way:

Gaining the blessing of the Elders and the permission of the spirits of the land tells me that we are heading in the right direction. Imagine how this conference would have turned out if we did not follow these protocols. We would probably have made some horrendous mistakes. (Michel 2002, 5.)

It is not unheard of in indigenous communities that epistemic authority depends on the speaker's age, or the person's status as an elder. This is of course inconsistent with Longino's (2002) criterion of tempered equality: the epistemic authority of the elders is determined by their social position. Nevertheless, the president of the conference adopted this social-epistemic practice. 
It may well be that this example proves to be unproblematic. Michel's words can be interpreted as a courtesy rather than an epistemological statement. It is also possible that such problematic principles are flexible and negotiable that the indigenous communities in question would, in the end, be prepared to renounce them in the context of a research project. However, if the epistemically privileged status of the elders ${ }^{5}$ happens to be something the indigenous epistemic communities in question will never give up in relevant situations, then it can prove difficult to integrate the knowledge systems in a way that would both satisfy the indigenous participants and meet the criteria formulated by Longino.

Moreover, there are other cases in which similar issues are at stake. For example, according to Linda Tuhiwai Smith, "Maori society valued knowledge highly, to such an extent that certain types of knowledge were entrusted only to a few members of the whanau" (Smith 1999, 172). If this kind of secrecy is indeed an essential part of the Maori knowledge system, and if it has to be preserved in situations when Maori knowledge is to be integrated with academic knowledge, the social-epistemic practices of the resulting epistemic community are not likely to meet Longino's criteria. It is in the nature of a secret that it cannot meet with effective outside criticism. In other words, the attempted integration would result in threatening the objectivity of the research community.

Now we know that in actual scientific practice information disclosure is not perfect, and we know that epistemic authority is not evenly distributed. Yet we agree with Longino in that perfect information disclosure is an ideal to be pursued and that epistemic authority is to be based on prior scientific achievements and not to be accepted on epistemically irrelevant grounds. Therefore, if an extra-academic knowledge system includes generally approved practices such as determining epistemic authority according to the speaker's age, or concealing certain types of knowledge because of their spiritual (or, say, commercial) value, and if these practices are inseparable parts of wholistic epistemic systems - then it is unfeasible to integrate these systems with academic knowledge.

\section{Conclusion: What extra-academic transdisciplinarity and scientific pluralism might learn from one another?}

\footnotetext{
${ }^{5}$ As to how significant a problem "gaining the permission of the spirits of the land" is, depends on what exactly it amounts to. If it is for instance comparable to prayer, and participation is optional, it might not jeoprdise the objectivity of the research community. On the other hand, if there are specific people in the community who have the power to determine whether the permission of the spirits has been achieved or not, it is inconsistent whith the criterion of tempered equality (Longino 2002).
} 
The non-philosophical literature on TD appears to be overly optimistic. We have argued that several ideas developed within pluralist philosophies of science have the potential of being of use when analysing problems and challenges presently passed over in this over-optimistic literature.

Attempts to integrate diverse knowledge systems often fail, and they may fail in a variety of ways. Sometimes problems in integration can be solved through mutual learning and deliberation, if given enough time, but this is not at all always so. This may be because scientific knowledge systems are theoretically incompatible, at least presently. The integration of academic knowledge systems with extra-academic knowledge systems can fail if the respective epistemic communities have inflexible conflicting epistemic values and norms that may be embedded in social-epistemic practices. The strong pressure on TD projects to rapidly generate integration may result in pseudo-integration and thereby jeopardise the reliability of the outputs of such projects. Moreover, the absence of operational peer communities and agreed-upon standards for evaluation makes the detection of such shortcomings difficult.

The notion of knowledge systems used in the TD literature resembles the anthropological notion developed for purposes in relation to which normative epistemic assessment is generally avoided. In discussions on extra-academic TD the concept is however used in contexts where normative epistemic assessment is indispensable and the epistemic norms and values of the different epistemic communities may be found to conflict with each other. If knowledge systems are to be integrated, they must be critically assessed. Combined with the optimistic idea that integration is to happen through mutual learning and deliberation, this notion of knowledge systems may result in decreased objectivity of research communities.

More interaction between the two broad bodies of literature would be welcome. This could prove useful for the development of socially inclusive research practices, and for the ongoing discussions of the roles that local communities, businesses, NGOs, indigenous people and others might play in scientific research. We suggest that pluralist philosophers of science sympathetic to some of the aims of TD would look more closely at actual TD research and the complex settings in which extra-academic collaboration and participation happen. It is important for progress in (our assessment of) extra-academic TD that it receives philosophical attention that recognises what is valuable in it, and that is capable of offering constructive criticism. The pluralist reasoning about extra-academic participation could do more than just concentrate on arguing why it is important to give extra-academic agents a role in academic research. It is equally important to ask how to do it well.

\section{Acknowledgements}


We thank Katri Huutoniemi, Kristina Rolin and the anonymous referees for many helpful comments and suggestions on earlier versions of the paper.

We acknowledge support by the Academy of Finland for the research required for writing this paper.

\section{References}

Agrawal, Arun. 1995. Dismantling the Divide between Indigenous and Western Knowleddge. Development and Change 26:3, 413-39.

Arabena, Kerry. 2010. All Knowledge is Indigenous. In V. A. Brown et. al. (eds.), Tackling Wicked Problems trough The Transdisciplinary Imagination. London and Washington DC: Earthscan, 260-270.

Biddle, Justin B. and Leuschner, Anna. Climate skepticism and the manufacture of doubt: can dissent in science be epistemically detrimental? European Journal for Philosophy of Science 5:3, 261-278.

Boghossian, Paul. 2006. Fear of Knowledge: Against Relativism and Constructivism. Oxford: Clarendon Press.

Brown, Mark. 2004. The Political Philosophy of Science Policy: Essay Review of Science, Truth, and Democracy by Philip Kitcher. Minerva: A Review of Science, Learning and Policy 42:1, 77-95.

Brown, Mark. 2013. Review of Science in a Democratic Society, by Philip Kitcher, Minerva: A Review of Science, Learning and Policy 51:3, 389-397.

Brown, Valerie A; Deane, Peter M.; Harris John A and Russell, Jacqueline Y. 2010. Towards A Just and Sustainable Future. In V. A. Brown et. al. (eds.), Tackling Wicked Problems trough The Transdisciplinary Imagination. London and Washington DC: Earthscan, 3-15.

Carew, Anna and Wickson, Fern. 2010. The TD Wheel: A Heuristic to Shape, Support and Evaluate Transdisciplinary Research. Futures 42, 1146-1155.

Cartieri, Francis and Potochnik, Angela. 2014. Toward Philosophy of Science's Social Engagement. Erkenntnis, 79(5), 901-916.

Chang, Hasok. 2012. Is Water $\mathrm{H}_{2} \mathrm{O}$ ? Evidence, Realism and Pluralism. Dordrecht, Heidelberg, New York and London: Springer.

Clarke, Steve and Walsh, Adrian. 2009. Scientific Imperialism and the Proper Relations between the Sciences. International Studies in the Philosophy of Science 23:2, 195-207.

Collins, Harry. 2010. Tacit and Explicit Knowledge. Chicago: University of Chicago Press.

Cooke, Bill and Kothari, Uma. 2001. Participation: The New Tyranny? London and New York: Zed Books.

Cullen-Unsworth, Leanne Claire; Hill, Rosemary; Butler, James R. A. and Wallace, Marilyn. 2011. A research process for integrating Indigenous and scientific knowledge in cultural landscapes: principles and determinants of success in the Wet Tropics World Heritage Area, Australia. The Geographical Journal 178:4, 351-365.

de Melo-Martin, I. \& Intemann, K. 2014. Are there limits to scientists' obligation to seek and engage dissenters? Synthese, 191(12), 2751-2765.

Douglas, Heather. 2007. Rejecting The Ideal of Value-Free Science. In H. Kincaid, J. Dupré and A. Wylie (eds.), Value-Free Science? Ideals and Illusions. Oxford: Oxford University Press, 120-139. 
Elzinga, Aant. 2008. Participation. In G. Hirsch Hadorn et al. (eds.), Handbook of Transdisciplinarity. Bern: Springer, 345-360.

Fehr, Carla and Plaisance, Kathryn S. 2010. Socially relevant philosophy of science: an introduction. Synthese 177, 301-316.

Fricker, Miranda. 2007. Epistemic Injustice: Power and the Ethics of Knowing. Oxford: Oxford University Press.

Harding, Sandra. 2011. Other Cultures' Sciences. In S. Harding (ed.), The Postcolonial Science And Technology Studies Reader. Durham and Londin: Duke University Press, 151-158.

Held, Hermann and Edenhofer, Ottman. 2008. Climate Protection vs. Economic Growth as a False Trade Off: Restructuring Global Warming Mitigation. In G. Hirsch Hadorn et al. (eds.), Handbook of Transdisciplinarity. Bern: Springer, 191-204.

Hirsch Hadorn, Gertrude; Biber-Klemm, Susette; Grossenbacher-Mansuy, Walter; Hoffmann-Riem, Holger; Joye, Dominique; Pohl, Christian; Wiesmann, Urs and Zemp, Elisabeth. 2008. The Emergence of Transdisciplinarity as a Form of Research. In G. Hirsch Hadorn et al. (eds.), Handbook of Transdisciplinarity. Bern: Springer, 19-42.

Hirsch Hadorn, Gertrude; Pohl, Christian and Bammer, Gabriele. 2010. Solving Problems through Transdisciplinary Research. In R. Frodeman, J.T. Klein and K. Mitcham (eds.), Oxford Handbook of Interdisciplinarity. Oxford: Oxford University Press, 431-452.

King, Loren; Morgan-Olsen, Brandon and Wong, James. 2016. Identifying Difference, Engaging Dissent: What Is at Stake in Democratizing Knowledge? Foundations of Science, 21(1), 69-88.

Kitcher, Philip. 1993. The Advancement of Science. New York: Oxford University Press.

Kitcher, Philip. 2001. Science, truth, and democracy, Oxford studies in philosophy of science. New York: Oxford University Press.

Kitcher, Philip. 2002. Reply to Helen Longino. Philosophy of Science 69, 569-572.

Kitcher, Philip. 2011. Science in a democratic society. Amherst, NY: Prometheus Books.

Kellert, Stephen H.; Longino, Helen E. and Waters, C. Kenneth. 2006. Introduction: The Pluralist Stance. In Kellert, S., H. Longino, and K. Waters (eds.), Scientific Pluralism.

Minnesota Studies in the Philosophy of Science XIX. Minneapolis: University of Minnesota Press, vii-xxix.

Koskinen, Inkeri. 2014. Critical Subjects: Participatory Research Needs to Make Room for Debate. Philosophy of the Social Sciences, 44(6), 733-75.

Leavy, Patricia. 2011. Essentials of Transdisciplinary Research: Using Problem-Centered Methodologies. Walnut Creek, CA: Left Coast Press.

Longino, Helen E. 1990. Science as Social Knowledge: Values and Objectivity in Scientific Inquiry. Princeton: Princeton University Press.

Longino, Helen E. 2002a. The Fate of Knowledge. Princeton and Oxford: Princeton University Press.

Longino, Helen E. 2002b. Reply to Philip Kitcher. Philosophy of Science 69, 573-577.

Mäki, Uskali. 1997. The one world and the many theories. In A. Salanti and E. Screpanti (eds.), Pluralism in Economics, Cheltenham: Edward Elgar, 37-47.

Mäki, Uskali. 2013. Scientific Imperialism: Difficulties in Definition, Identification, and Assessment. International Studies in the Philosophy of Science 27:3, 325-339.

Messerli, Bruno and Messerli, Paul. 2008. From Local Projects in the Alps to Global Change Programmes in the Mountains of the World: Milestones in Transdisciplinary 
Research. In G. Hirsch Hadorn et al. (eds.), Handbook of Transdisciplinarity. Bern: Springer, 43-62.

Michel, Henry. 2002. Conference Welcome. In H. Michel and D. V. Gayton (eds.), Linking Indigenous Peoples' Knowledge and Western Science in Natural Resource Management. Conference Proceedings. Southern Interior Forest Extension and Research Partnership, Kamloops, B.C. SIFERP Series 4, 3-6.

Michel, Henry and Gayton, Donald V. (eds.). 2002. Linking Indigenous Peoples' Knowledge and Western Science in Natural Resource Management. Conference Proceedings. Southern Interior Forest Extension and Research Partnership, Kamloops, B.C. SIFERP Series 4.

Mitchell, Sandra. 2004. Why integrative pluralism? E :CO 6:1-2, 81-91.

Mitchell, Sandra. 2004. Biological Complexity and Integrative Pluralism. Cambridge: Cambridge University Press.

Mobjörk, Malin. 2010. Consulting versus participatory transdisciplinarity: A refined classification of transdisciplinary research. Futures, 42, 866-873.

Nowotny, Helga; Scott, Peter and Gibbons, Michael. 2001. Re-Thinking Science: Knowledge and the Public in an Age of Uncertaintly. Cambridge: Polity.

Pohl, Christian; Kerkhoff, Lorrae van; Hirsch Hadorn, Gertrude and Bammer, Gabriele. 2008. Integration. In G. Hirsch Hadorn et al. (eds.), Handbook of Transdisciplinarity. Bern: Springer, 411-426.

Pohl, Christian. 2008. From science to policy through transdisciplinary research. Environmental science \& policy 11:1, 46-53.

Pohl, Christian. 2011. What Is Progress in Transdisciplinary Research? Futures 43, 618626.

Polanyi, Michael. 1966. The Tacit Dimension. London: Routledge.

Raymond, Christopher; Fazeyc, Ioan; Reed, Mark S.; Stringerf, Lindsay C.; Robinson Guy M.; Evel, Anna C. 2010. Integrating Local And Scientific Knowledge for Environmental Management. Journal of Environmental Management 91, 1766-1777.

Rip, Arie. 2008. Nanoscience and Nanotechnologies: Bridging Gaps Through Constructive Technology Assessment. In G. Hirsch Hadorn et al. (eds.), Handbook of Transdisciplinarity. Bern: Springer, 145-158.

Rolin, Kristina. 2011. Contextualism in Feminist Epistemology and Philosophy of Science. In H. E. Grasswick (ed.), Feminist Epistemology and Philosophy of Science: Power in Knowledge. Dodrecht, Heidelberg, London and New York: Springer, 25-44.

Russell, A. Wendy; Wickson, Fern and Carey, Anna L. 2008. Transdisciplinarity: Context, contradictions and capacity. Futures 40:5, 460-472.

Sillitoe, Paul and Marzano, Mariella. 2009. Future of Indigenous Knowledge Research in Development. Futures 41, 13-23.

Smith, Linda Tuhiwai. 1999. Decolonizing Methodologies: Research and Indigenous Peoples. London: Zed Books.

Solomon, Miriam. 2006. Groupthink versus The Wisdom of Crowds: The Social Epistemology of Deliberation and Dissent. The Southern Journal of Philosophy 44: 28-42.

Solomon, Miriam. 2008. Norms of Dissent. In Damien Fennell (ed.]. Contingency and Dissent in Science Project Discussion Paper Series .Technical Report 0908, CPNSS, LSE. 
Solomon, Stephanie. 2009. Stakeholders or Experts? On the Ambiguous Implications of Public Participation in Science. In J. Van Bouwel (ed.), The Social Sciences and Democracy. London: Palgrave Macmillan, 39-61.

Star, Susan and Griesemer, James. 1989. Institutional Ecology, 'Translations' and Boundary Objects: Amateurs and Professionals in Berkeley's Museum of Vertebrate Zoology, 1907-39. Social Studies of Science 19:3, 387-420.

Thorén, Henrik and Breian, Line. 2015. Stepping stone or stumbling block? Mode 2 knowledge production in sustainability science. Studies in History and Philosophy of Science Part C: Studies in History and Philosophy of Biological and Biomedical Sciences. Available online 10 December 2015.

Van Bouwel, Jeroen. 2009a. Where the Epistemic and the Political Meet: An Introduction to the Social Sciences and Democracy. In J. Van Bouwel (ed.), The Social Sciences and Democracy. London: Palgrave Macmillan, 1-16.

Van Bouwel, Jeroen. 2009b. The Problem With(Out) Consensus: The Scientific Consensus, Deliberative Democracy and Agonistic Pluralism. In J. Van Bouwel (ed.), The Social Sciences and Democracy. London: Palgrave Macmillan, 121-142.

Van Bouwel, Jeroen. 2013. Sandra Mitchell: Unsimple Truths. Science, Complexity, and Policy. Book review. Science \& Education 22: 2, 411-418.

Van Bouwel, Jeroen. 2015. Towards Democratic Models of Science: Exploring the Case of Scientific Pluralism. Perspectives on Science 23:2, 149-172.

Van Der Steen, Wim J. 1993. Towards disciplinary disintegration in biology. Biology and Philosophy 8 (3), 259-275.

Vayda, Andrew P.; Walters, Bradley B. and Setyawati, Indah. 2004. Doing and knowing: questions about studies of local knowledge. In Bicker, A., P. Sillitoe, \& J. Pottier (eds.), Investigating Local Knowledge: New Directions, New Approaches. London: Ashgate, 35-58.

Whitt, Laurelyn. 2009. Science, Colonialism, and Indigenous Peoples: The Cultural Politics of Law and Knowledge. Cambridge: Cambridge University Press.

Wickson F., A.L Carew, and A.W. Russell. 2006. Transdisciplinary research: characteristics, quandaries and quality. Futures 38, 1046-1059.

Wylie, Alson. 2011. Epistemic Justice, Ignorance, and Procedural Objectivity-Editor's Introduction. Hypatia 26:2, 233-235.

Wylie, Alison. 2015. A Plurality of Pluralisms: Collaborative Practice in Archaeology. In F. Padovani, A. Richardson, and J. Y. Tsou (eds.), Objectivity in Science: New Perspectives from Science and Technology Studies. Boston Studies in the Philosophy and History of Sciences. Dordrecht: Springer, 189-210.

Zierhofer, Wolfgang and Burger, Paul. 2007. Disentangling Transdisciplinarity: An Analysis of Knowledge Integration in Problem-Oriented Research. Science Studies 20:1, 51-74. 